\title{
Peak expiratory flow rate in normal school children (5-15 Years) of Vizianagaram district- A cross-sectional study
}

\author{
J. R. Rajasekhar ${ }^{1}$, V.Sunita ${ }^{2, *}$, K. Madhusudan Rao ${ }^{3}$, P. Padma Priyanka ${ }^{4}$ \\ ${ }^{1,4}$ Post Graduate, ${ }^{2}$ Associate, ${ }^{4}$ Professor, Dept. of Paediatrics, Maharajah's Institute of Medical Sciences \& Medical College, \\ Andhra Pradesh, India
}

*Corresponding Author:

Email: sunitavegesna1@gmail.com

\begin{abstract}
Introduction: PEFR is a simple bedside tool to assess the degree of airway obstruction in asthmatic children. As it is influenced by age, anthropometric data, racial and ethnic differences, region specific nomograms have been advocated for use. This study has been undertaken with a view to establish reference values for PEFR and develop nomograms in Vizianagaram district.

Material and Methods: The present study was undertaken at MIMS medical college, Vizianagaram. The main aim of this school based, cross-sectional, descriptive study was to establish standard nomograms of PEFR for healthy school going children between 5-15 years age group. A total of 2684 students were included in the study after meeting the inclusion criteria. PEFR values were recorded with mini-Wright peak flow meter. Body surface area and body mass index were calculated from height and weight. Statistical analysis was carried out using $\mathrm{R}$ version 3.4.2.
\end{abstract}

Results: PEFR showed high positive correlation with respect to Height, Weight, Age, Body Surface area and moderate positive correlation with BMI. Separate regression models were developed for boys and girls.

Conclusions: PEFR had positive correlation with height, age, weight, BMI and BSA.PEFR values of children in Vizianagaram district were lesser than those of other south Indian, north Indian and western children.

Keywords: PEFR, mini-Wright peak flow meter, linear regression equations, asthma morbidity, nomograms.

\section{Introduction}

The burden of childhood asthma is steadily increasing in Indian children. The recent guidelines for asthma management advocate the use of PEFR for diagnosis as well as for monitoring treatment, especially in children more than 5 years. It is a simple and reliable way of judging the degree of airway obstruction in obstructive respiratory diseases, specifically asthma. The utility of peak flow meter in management of asthma is akin to the role of glucometer in diabetes mellitus. It provides an objective evidence of asthma control and is very useful in predicting an impending attack. It increases self -reliance and active participation of the patient in the management of asthma.

The peak expiratory flow rate (PEFR) is the maximum flow rate generated during a forceful exhalation and is expressed in litres/minute. PEFR is easily measured by using a mini-Wright peak flow meter (m-WPFM). ${ }^{1}$ Ideally, the patient's measured best is the most appropriate reference value but in it's absence, population based nomograms for PEFR may need to be considered. Many studies done in the past, have established that PEFR is dependant on a number of variables like age, sex, anthropometric data, racial and ethnic differences. So region-specific nomograms for PEFR $^{2}$ have been advocated for clinical use. Although a number of studies ${ }^{3-5}$ have been done from different parts of India, there was limited data from north-coastal districts of Andhra Pradesh and hence the need for this study.

\section{Material and Methods}

This study was undertaken at MIMS medical college, vizianagaram. The main aim of this school based, cross-sectional, descriptive study was to establish standard nomograms of PEFR for healthy school going children between 5-15 years of age, to correlate PEFR to anthropometric data and to build a predict model for prediction of PEFR based on anthropometric data. Study was conducted over a period of two years from October 2015 to October 2017 and was initiated after obtaining approval from the Institutional Ethics Committee.

Five schools were randomly selected, which included two private schools in vizianagaram town and three government schools from surrounding villages. Healthy students in the age group of 5-15 years were included in the study. Students with acute respiratory infection in the preceding week, a personal or family history of wheezing, nocturnal cough or tuberculosis, wheeze or crepitations on auscultation, chest deformities and any major involvement of cardiac and respiratory system were excluded from the study.

Necessary permission from the concerned authority (school head master / principal) and parents was obtained .Out of the 3000 students who were screened, 2684 were eligible for the study. A detailed history was taken in all these students and a thorough physical examination was carried out. Weight was measured in the upright position to the nearest $0.1 \mathrm{~kg}$ using calibrated electronic balance and height was measured without shoes to the nearest 0.1 $\mathrm{cm}$ using calibrated stadiometer. BMI (body mass index) was calculated from height and weight (using formula 
Weight in $\mathrm{kg} /$ height in metre ${ }^{2}$ ). BSA (Body surface area) was calculated from height and weight (using formula square root of weight in $\mathrm{kg} \times$ height in $\mathrm{cm} / 3600)$.

Six well functioning mini-Wright Peak Flow Meters (m-WPFM), 3 low range (50-350 1/min) and 3 standard range (60-800 1/min) models, were used to record PEFR (L/min). Standard range model was used when PEFR values $>3501 / \mathrm{min}$ were found. The purpose and technique of the test was explained in detail to all the students and it was followed by a demonstration of its performance. The test should be performed in the standing position, holding the peak flow meter horizontally, without interfering with the movement of the marker or covering the slot. He or she should be asked to take a deep breath and then exhale by forceful expiration as fast as possible, after maintaining an airtight seal between lips and mouthpiece of the instrument. Most of the students were given a trial for 45 times to familiarise them with the procedure, and then three serial blows were recorded. An average of 40 samples were collected in each day for a total of 70 days visits.

The data comprised PEFR values, which were processed for mean and standard deviation. Age, height, weight, BMI and Body surface area were the independent variables, while PEFR value was the dependent variable. Student's unpaired t-test was used to compare the PEFR values between various groups. $\mathrm{P}<0.05$ was considered statistically significant, while $\mathrm{P}<0.001$ was considered statistically highly significant. Regression equations based on age and height were constructed for both boys and girls based on the statistical significance of independent variables. Correlation between age, height, weight, and PEFR was done using Pearson's correlation. The statistical analysis was carried out with $\mathrm{R}$ version 3.4.2.

\section{Results}

A total of 2684 students across the age range of $5-$ 15 years were included in this study. There was a skewed distribution of the age in the overall population because the government schools were exclusively high schools and thus had children with a lower age limit of 108 months. The students were highest in the age group of 13 years $(21 \%$ of the total students), followed by 14 years (16\% of the total students) and lowest in 5-years age band ( $2 \%$ of the total students). Out of the 2684 students, 1364 were boys and 1320 were girls. There were far more boys than girls in the population but it was sampled in such a way, so as to maintain nearly equal proportion of boys and girls in this study.

The anthropometric measurements such as height and Weight were recorded for all the students. BMI for females was in the range of $14-23$ while for males it was in the range of 14.5-23, emphasizing the fact that only healthy children were considered for the study. Body surface area (in sq.m) was calculated using Mosteller formula. Along with the anthropometric measurements, PEFR (I/min) was recorded for all the students. There were three readings taken for PEFR (I/min). Based on PEFR recordings, average PEFR of the three recordings was calculated as the mean of three readings. The best of the three recordings that is the maximum PEFR (1/min) value was used in all statistical analysis. The mean of average PEFR (I/min) for females was $228.75(\mathrm{I} / \mathrm{min}) \pm 64.41$ whereas for males it was $254.67(\mathrm{I} / \mathrm{min}) \pm 62.07$. The mean of $\max$ PEFR $(\mathrm{I} / \mathrm{min})$ for females was $242.72(\mathrm{I} / \mathrm{min}) \pm 65.38$ whereas for males it was $275.81(\mathrm{I} / \mathrm{min}) \pm 65.35$.

Table 1: Gender wise comparison of PEFR by Age

\begin{tabular}{|l|c|c|c|c|}
\hline $\begin{array}{c}\text { Age Slabs } \\
\text { (in months) }\end{array}$ & $\begin{array}{c}\text { Mean for Max } \\
\text { PEFR (Female) }\end{array}$ & $\begin{array}{c}\text { Mean for Max } \\
\text { PEFR (Male) }\end{array}$ & t-statistic & p value \\
\hline $60-71$ & 126 & 142 & -3.44 & $<0.001$ \\
\hline $72-83$ & 124 & 148 & -6.21 & $<0.001$ \\
\hline $84-95$ & 128 & 157 & -6.72 & $<0.001$ \\
\hline $96-107$ & 171 & 207 & -8.52 & $<0.001$ \\
\hline $108-119$ & 204 & 229 & -4.98 & $<0.001$ \\
\hline $120-131$ & 236 & 252 & -4.29 & $<0.001$ \\
\hline $132-143$ & 255 & 277 & -14.70 & $<0.001$ \\
\hline $144-155$ & 268 & 276 & -3.36 & $<0.001$ \\
\hline $156-167$ & 286 & 305 & -6.24 & $<0.001$ \\
\hline $168-179$ & 296 & 339 & -13.30 & $<0.001$ \\
\hline $180-191$ & 299 & 348 & -10.29 & $<0.001$ \\
\hline
\end{tabular}

From Table 1, we can see that PEFR $(1 / \mathrm{min})$ is higher in boys as compared to girls across all the age slabs. The difference is significant which can be seen from the $\mathrm{p}$ value. Also PEFR is increasing with an increase in the age. The PEFR in age slab of 72-83 months for females is lesser than that seen in age slab of 60-71 months and this could be due to the sample that was selected, where it was possible that people in 72-83 months age group had smaller heights. As the numbers in this age group are significantly low it wouldn't impact the regression model. 
Table 2: Gender wise comparison of PEFR by Height

\begin{tabular}{|c|c|c|c|c|}
\hline $\begin{array}{c}\text { Height slab } \\
\text { (in cm) }\end{array}$ & $\begin{array}{c}\text { Mean for Max } \\
\text { PEFR (Female) }\end{array}$ & $\begin{array}{c}\text { Mean for Max } \\
\text { PEFR (Male) }\end{array}$ & t-statistic & P value \\
\hline $100-109$ & 121 & 143 & -7.44 & $<0.001$ \\
\hline $110-119$ & 136 & 158 & -5.94 & $<0.001$ \\
\hline $120-129$ & 178 & 213 & -8.59 & $<0.001$ \\
\hline $130-139$ & 238 & 252 & -4.45 & $<0.001$ \\
\hline $140-149$ & 260 & 278 & -9.68 & $<0.001$ \\
\hline $150-159$ & 280 & 294 & -6.28 & $<0.001$ \\
\hline $160-169$ & 304 & 331 & -8.35 & $<0.001$ \\
\hline $170-179$ & 336 & 371 & -6.96 & $<0.001$ \\
\hline $180-189$ & - & 383 & - & - \\
\hline
\end{tabular}

From Table 2, we can see that PEFR ( $1 / \mathrm{min})$ was significantly higher in boys in comparison to girls across all the height slabs. Also, PEFR was increasing with an increase in the height. There were no females in the height slab of $180-189 \mathrm{~cm}$ and thus $t$ test couldn't be performed to ascertain the difference in PEFR ( $1 / \mathrm{min})$ between males and females. But as PEFR $(1 / \mathrm{min})$ was significantly higher in males as compared to females in all other height slabs it can be concluded that males have significantly higher PEFR ( $1 / \mathrm{min})$ than females. The pvalue of $t$-test to compare PEFR in private and government schools (urban and rural respectively) was equal to 0.67 , which signifies that there was no difference in PEFR between urban and rural children.

As there was a significant difference in the means of PEFR and the anthropometric data between females and males, the need for separate regression formulas for males and females was tested using Welch two sample ttest and based on the results from welch t-test (The pvalues were consistently $<0.01$ ) it was evident that, both genders need to be treated differently. This implied that different regression models were required for females and males.

The impact of independent variables (Age, Height, Weight, BSA, BMI) on the dependent variable (PEFR) was studied using correlation. Max PEFR had a correlation of $91 \%$ with height, $89 \%$ with Age and $88 \%$ with weight. BMI had the lowest collinearity of $62 \%$ with Max PEFR and thus wasn't considered for regression model. Max PEFR also had 90\% correlation with body surface area but as height and body surface area had $98 \%$ correlation, both could not be included in the model and so only height and age were considered for the regression model. Thus based on the correlation coefficients and multi-collinearity, only height and age were retained as independent variables for the regression model.

The aim of deriving a linear regression model is to establish a linear relationship (a mathematical formula) between the predictor variable(s) and the response variable, so that, this formula can be used to estimate the value of the response $\mathrm{Y}$, when only the predictors $(\mathrm{Xs})$ values are known. In the present data, max PEFR (of 3 readings) was the response variable and Age (in months), Height (in $\mathrm{cm}$ ) and Weight $(\mathrm{Kg})$ were the Predictors, selected based on their correlation coefficients. The predictors were tested for significance and only the significant variables were considered in the model.

The below regression equation was useful to predict PEFR for females based on the height and age. Weight was not included as it was not highly significant. The estimates for the model intercept is-159.863 and the coefficient measuring the slope of the relationship with Height is 2.04636 and coefficient measuring the slope of the relationship with Age is 0.8042 . As the Height or Age increases so does the PEFR ( $1 / \mathrm{min})$. The $p$-value is shown as $2 \mathrm{e}-16$ which means the $\mathrm{p}$-value is less than $2 \mathrm{x}$ $10^{\wedge-16 .}$.

\section{PEFR $=-\mathbf{1 5 9 . 8 6 3}+\mathbf{0 . 8 0 4 2} \times$ Age $($ in months) $+\mathbf{2 . 0 4 6} \times$ Height (in cm)}

The below regression equation is useful for predicting PEFR in males.

PEFR $=-\mathbf{1 4 1 . 5 2 3}+0.806 \times$ Age $($ in month $)+2.066 \times$ Height (in cm)

The estimates for the model intercept is -141.523 and the coefficient measuring the slope of the relationship with Height is 2.066 and coefficient measuring the slope of the relationship with Age is 0.806 . Weight was not a significant variable in case of males.

Nomograms are used to visually calculate PEFR $(1 / \mathrm{min})$ based on height and age. It was observed that as the age and height increases, PEFR also increases in the case of both females (Fig. 1) and males (Fig. 2). But the PEFR in females was lower than in males across all height and age slabs. The below figures show the nomograms to calculate PEFR for females and males based on the height. The PEFR can be visually calculated based on the nomograms and it also gives a distribution of values in the data. 


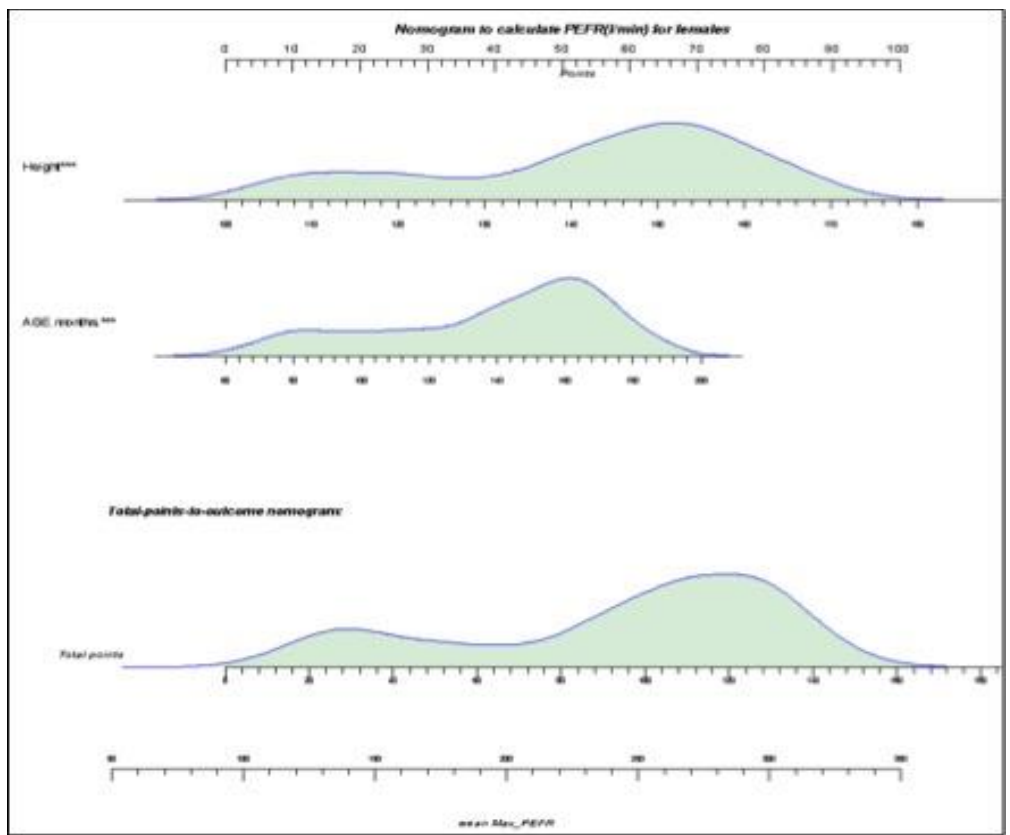

Fig. 1: Nomogram to calculate PEFR (1/min) for females

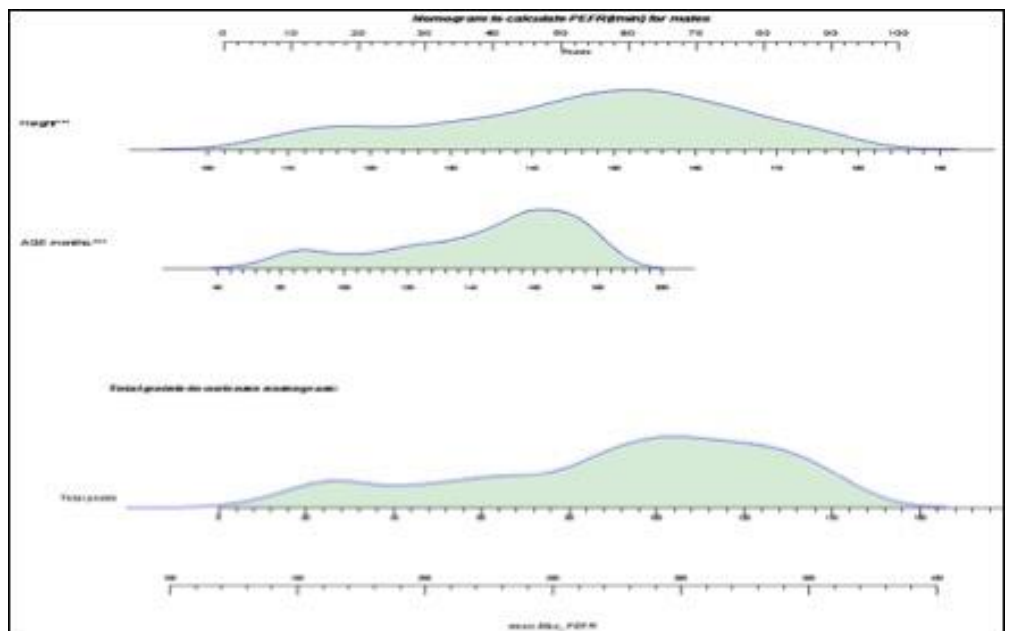

Fig. 2: Nomogram to calculate PEFR (1/min) for males

\section{Discussion}

The peak expiratory flow rate (PEFR) measurement is a simple, reproducible and reliable way of judging the degree of airway obstruction in various obstructive pulmonary diseases, specifically asthma. PEFR is easily measured by using a mini-Wright peak flow meter (m-WPFM) ${ }^{1}$ which is easy to use and reliable. It can be recorded even by the patients or by the parents at home. ${ }^{6-8}$

Nomograms and regression equations for predicting PEFR from height are available for Western children $^{9}$ and normal values of PEFR in relation to age, sex, height and weight are available from different countries $^{10-13}$ as well as from different parts of India but no such standard reference values are available from north-coastal districts of Andhra Pradesh and hence the need for this study.

The present study comprised of 2684 students in the age group of 5-15 years with the highest number of students documented in the age group of 13 years (21\% of the total students), followed by 14 years (16\% of the total students) and the lowest number in 5 years age band ( $2 \%$ of the total students). Thus majority of the students were from higher age bands as compared to lower age bands. Out of the 2684students, 1364 were boys and 1320 were girls. Students were randomly selected from 5 schools, two of which were in urban areas and three in rural areas.

The impact of ethnicity on PEFR (1/min) values was reported in a number of studies. Studies done by Singh HD et al,$^{14}$ swaminathan et $\mathrm{al}^{3}$ Mahajan KK et $\mathrm{al},{ }^{15}$ Ramachandra et $\mathrm{al}^{16}$ and Malik SK et $\mathrm{al}^{4}$ showed 
that south Indian children had lower PEFR values in comparison to north Indian children who in turn had lesser PEFR values when compared to their western counterparts as evidenced by studies done by Godfrey $S$ et al, ${ }^{9}$ Carson JWK et al, ${ }^{17}$ Sanz et al $^{18}$ and Host A et al. ${ }^{11}$ In the present study, PEFR values were low in comparison to North Indian children. In contrast, the study conducted by Parmar et $\mathrm{al}^{19}$ showed that PEFR values in healthy North Indian school children were similar to the findings from the western countries.

Malik et $\mathrm{al}^{4}$ conducted a study on PEFR on school children in Punjab and found that the height and the standardized value of PEFR showed no rural-urban differences. In studies done by Paramesh et al, ${ }^{20}$ Glew et $\mathrm{al}^{21}$ and Pasek et $\mathrm{al}^{22}$ there was no statistically significant difference between PEFR of urban and rural children in different parts of the world. But studies done in North India by Budhiraja et $\mathrm{al}^{23}$ showed a significant difference between urban and rural children, with urban children having better PEFR. In the present study, pvalue of t-test to compare PEFR in private and government schools (located in urban and rural areas respectively) was equal to 0.67 which signifies that there was no difference in PEFR between urban and rural children.

Age had a significant positive correlation with PEFR in studies that were conducted by Primhak et al, ${ }^{24}$ 1984 and Carson JWK et al, ${ }^{17}$ 1989. In the present study also, age had positive correlation with PEFR, in both males and females. On the contrary, in a study done by Srinivas P et al, ${ }^{25} 1999$,on elderly people in Malaysia, age was found to have negative correlation with PEFR.

Highest values of PEFR were documented in the age range of 14-15 years in the present study. This observation was consistent with other studies conducted by other workers, though the age at which the maximum PEFR was reached is different and peaked post puberty or adolescence. The difference in this observation was because present study was conducted in the age groups of 5-15 years and higher age groups were excluded. Nairn et $\mathrm{al}^{26}$ found maximum mean PEFR at 17 years in both males and females. In a study done by Bayu et $\mathrm{al}^{27}$ on Ethiopian children, a sharp increase in PEFR with age was documented reaching a peak at 17-18 years in males and somewhat earlier at 15-16 years in the female group. Rahman et $\mathrm{al}^{28}$ recorded PEFR on Bangladeshi boys and girls and found that PEFR continued to rise in boys after 15 years but PEFR in girls seemed to have attained maximum value by that age. Sherill DL et $\mathrm{al}^{29}$ conducted a study to assess the impact of age on PEFR and found that there was sudden change in lung function during the adolescent growth spurt. The PEFR values had a steep jump in both girls and boys at post pubertal age as compared with puberty age i.e., 12 to 14 years. This observation of increasing PEFR ( $1 / \mathrm{min})$ with age could possibly be due to rapid growth of airway passages and increase in muscularity as the age advances.

The effect of gender on PEFR was documented in a number of studies. Previous studies done by Hameed et $\mathrm{al}^{30}$ Kashyapet $\mathrm{al},{ }^{31}$ Host et $\mathrm{al}^{11}$ and Pande et al ${ }^{10}$ reportedhigher PEFR values in males in comparison with females. In the present study also, a significant difference was noticed in the PEFR values of males and females with males recording higher values. Male children had comparatively higher PEFR values, especially after the age of 10 years, possibly because of better height, weight, rapid growth of airway passages as age advances and possibly due to more expiratory muscle effort. In contrast, Paramesh et $\mathrm{al}^{20}$ and Primhak $\mathrm{R}$ et $\mathrm{al}^{24}$ reported that the values of PEFR were similar in both males and females.

Max PEFR had a correlation of $91 \%$ with height, $88 \%$ with Age and $87 \%$ with Weight. Thus based on the correlation coefficients and multi-colinearity, height and age were retained as independent variables for constructing the regression equation to predict PEFR in the present study. Both height and age are convenient to record and its assessment is accurate, if proper technique is used. Host A et al, ${ }^{11} 1994$ observed that height and age together had better predicted accuracy than height alone. The prediction equations in the present study are as follows.

\section{PEFR(females) $=-\mathbf{1 5 9 . 8 6 3}+\mathbf{0 . 8 0 4 2} \times$ Age $($ in months) $+2.046 \times$ Height $($ in $\mathrm{cm})$}

\section{$\operatorname{PEFR}($ males $)=-141.523+0.806 \times$ Age $($ in month $)+$ $2.066 \times$ Height $($ in cm)}

A number of studies done in the past have utilised height alone or height, age and weight to construct prediction equations for PEFR. Swaminathan et $\mathrm{al}^{3}$ studied PEFR in South Indian children and concluded that PEFR increased progressively with age and showed a good correlation to height, age and weight in both the sexes. The prediction equations as proposed by Swaminathan et al, ${ }^{3}$ for boys and girls based on height, weight and age are given below.

\section{PEFR $($ males $)=(2.04 \times$ Height in $\mathrm{cm})+(4,78 \times$ age in years $)+(2.73 \times$ Weight in $\mathrm{kg})-134.29$.}

\section{PEFR $($ females $)=(2.03 \times$ Height in $\mathrm{cm})+(3.18 \times$ Age in years) + 2.71 Weight in kg) - 132.92}

Sharma et $\mathrm{al}^{32}$ and Chowgule et $\mathrm{al}^{34}$ have proposed regression equations based on height, weight and age while Vijayan et $\mathrm{al}^{33}$ constructed prediction equation for PEFR based on height and weight only.

\section{Conclusion}

PEFR had significant positive correlation with height. It was also found to increase with age, weight, 
BMI and BSA. Predictive equations were derived, relating the PEFR with height and age. Nomograms were established for both females and males separately so that they can be used as preliminary references to establish PEFR values of other children in this region, based on height and age. PEFR values of children of Vizianagaram district were lesser than those of other south Indian, north Indian and western children.

Funding: No funding sources.

Conflict of interest: None declared.

\section{References}

1. Wright BM.A miniature Wright peak- flow meter. $\mathrm{Br}$ Med J 1978;2(6152):1627- 28.

2. CB M, SC K, Babu M. Peak Expiratory Flow Rate In Healthy Rural School Going Children (5-16 Years) of Bellur Region For Construction of Nomogram. Journal of Clinical and Diagnostic Research : JCDR 2013;7(12):2844-46.

3. Swaminathan S, Venkatesan P, Mukunthan R. Peak expiratory flow rate in South Indian Children. Indian Pediatr 1993;30:207-10.

4. S.K. Malik, S.K. Jindal, P.K. Sharada and N. Banga. "Peak expiratory flow rate of healthy school boys from Punjab". Indian Pediatr 1981;18:517-21.

5. Kashyap S., Puri DS, Bansal SK. "Peak expiratory flow rates of healthy tribal children living at high altitudes in the Himalayas". Indian Pediatr 1992;29:283-86.

6. S. Wille, K. Svensson. Peak flow in children aged 4-16 years. Acta Pediatrica 1989;78(4):544-48.

7. De Hamel FA.The mini Wright peak flow meter as lung function measuring device. $N Z$ Med $J$ 1982;95:666-69.

8. Perks WH, Cole M, Steventon RD, Tams IP, Prowse K .An evaluation of the vitalograph Monitor. Br J Dis Chest 1981;75:161-64.

9. Godfrey S, Kamburof PL, Nairn JR. Spirometry, lung volumes and air ways resistances in normal children aged 5-18 year". Br J Dis Chest 1970;64:15-24.

10. Pande IN, Mohan, Khilnani S, Khilnani GC. Peak expiratory flow rates in school going children. Indian $J$ Chest Dis Allied Sci 1997;39(2):87-95.

11. A Host, AH Host, T Ibsen. Peak expiratory flow rate in healthy children aged 6-17 years. Acta Paediatrica 1994;83(12):1255-57.

12. Jaya SI and Fagbenro AO. Peak expiratory flow rates of Carpet weaving children. Indian Pediatr 1995;33(2):10508.

13. Joshi SK, Sharma P, Sharma V, Sitaraman S, Pathak SS. Peak expiratory flow rates in Nigerian school children. Afr J Med Med Sci 1996;24(4):379-84.

14. Singh HD, Peri S. Peak expiratory flow rate in South Indian children and adolescents. Indian Pediatr 1978;11:473-78.

15. Mahajan KK, Mahajan SK, Maini BK, Srivastava SC. Peak expiratory flow rate and its Prediction Formula in Haryanavis. Indian J Physiol Pharma 1984:28:319-25.

16. Ramachandra K, Srinivasaiah S, Giliyaru S, Eregowda A. Study of PEFR in urban lower and middle class high school children at Bangalore, India. Int J Contemp Pediatr 2016;3(1):189-92.

17. Carson JWK, Hoey H, Taylor MRH. Growth and other factors affecting peak expiratory flow rate. Arch Dis Child 1989;64:96-102.
18. Sanz J, Martorell A, Saiz R, Alvarez V, Carigasco Jl. Peak expiratory flow measured with the Mini Wright Peak Flow Meter in children. Pediatr Pulmonol 1990;9(2):86-90.

19. Parmar VR, Kumar L, Malik SK. Normal values of peak expiratory flow rate in healthy North Indian school children. 6-16 years of age. Indian Pediatr 1977;14:59194.

20. Paramesh $\mathrm{H}$. Normal peak expiratory flow rate in urban and rural children. Indian J Pediatr 2003;70:375-77.

21. Glew RH, Kassam H, Vander Voort J, Agaba PA, Harkins M, Vander Jagt DJ. Comparison of pulmonary function between children living in rural and urban areas in northern Nigeria. J Trop Pediatr 2004;50(4):209-16.

22. Pasek M, Jerzemowski J. Respiratory System Parameters and Other Somatic Indicators of Fitness in Primary School Pupils Exemplified in the Pomeranian Province. Baltic Journal of Health and Physical Activity (c) Gdansk University of Physical Education and Sport in Gdansk. 2011;3(4):293-8.

23. Budhiraja S, Singh D, Pooni PA, Dhooria GS. Pulmonary functions in normal school children in the age group of 615 years in north India. Iran J Pediatr 2010;20(1):82-90.

24. Primhak RA, Biggins JD, Tsanakas JN, Hatzimichael A, Millnar RD, Karponzas JG.Factors affecting the peak expiratory flow rate in children. $\mathrm{Br} J$ Dis Chest 1984;78(1):26-35

25. Srinivas P, Chia YC, Poi PJ, Ebrahim S. Peak expiratory flow rate in elderly Malaysians. Med J Malaysia 1999;54(1):11-21.

26. Nairn JR, Bennett AJ, Andrew JD, MacArthur P.A study of respiratory function in normal school children. Arch Dis Child 1962;36:253-8.

27. Bayu T, Teshale S, Mills RJ. Peak expiratory flow rate in normal Ethiopian children and adults in Addis Ababa. $\mathrm{Br}$ J Dis Chest 1987;81:176.

28. Rahman MA, Ullah MB, Begum A. Lung function in teenage Bangladeshi boys and girls. Respir Med 1990;84:47-55.

29. Sherill DL, Camilli A, Lebowitz MD. On the temporal relationship between lung function and somatic growth. Am Respir Dis 1989;140:638-44.

30. Hameed MA, Khan SA, Ahmed A. Pulmonary function studies in healthy Pakistani children. JPMA 1987;37:318 24.

31. Kashyap S, Malik SK. Peak expiratory flow rates in children of western Rajasthan, 7-14 years of age. Pak J Physiol 2012.

32. Sharma R, Jain A, Arya A, Chowdhary BR. Peak expiratory flow rate of school going rural children aged 5-14years from Ajmer district. Indian Pediatr 2002;39:75-8.

33. Vijayan VK, Kuppurao KV, Venkatesan P, Sankaran K, Prabhakar R. Pulmonary function in healthy young adult Indians in Madras. Throax 1990;45:611-5.

34. Chowgule RV, Shetye VM, Parmar jR. Lung function tests in normal Indian children. Indian Pediatr 1995;32(2):185-191.

How to cite the article: J. Rajasekhar, V. Sunita, Rao M., P. Priyanka. Peak expiratory flow rate in normal school children (5-15 Years) of Vizianagaram district- A cross-sectional study. IP Int J Med Paediatr Oncol 2018;4(3):119-124. 